\title{
Perceived Conflict Styles of Adult Children and their Parents: What Is the Connection?
}

\author{
Dean M. Busby \\ Brigham Young University - Provo, dean_busby@byu.edu \\ Lena Hsin-Yao Chiu \\ Brigham Young University - Provo
}

Follow this and additional works at: https://scholarsarchive.byu.edu/facpub

Part of the Other Social and Behavioral Sciences Commons

\section{Original Publication Citation}

Busby, D. M., \& Chiu, H-Y. (2017). Perceived conflict styles of adult children and their parents:

What is the connection? Journal of Child and Family Studies, 26: 3412-3424.

\section{BYU ScholarsArchive Citation}

Busby, Dean M. and Chiu, Lena Hsin-Yao, "Perceived Conflict Styles of Adult Children and their Parents: What Is the Connection?" (2017). Faculty Publications. 4629.

https://scholarsarchive.byu.edu/facpub/4629 


\title{
Perceived Conflict Styles of Adult Children and their Parents: What Is the Connection?
}

\author{
Dean M. Busby ${ }^{1} \cdot$ Lena Hsin-Yao Chiu ${ }^{1}$
}

Published online: 15 July 2017

(C) Springer Science+Business Media, LLC 2017

\begin{abstract}
The purpose of this study was to explore the potential genesis of conflict styles for couples by evaluating the association between parents' conflict styles and those of their adult children and their adult children's partners. Using Social Learning Theory as a theoretical foundation, the four conflict typologies from Gottman's work (avoidant, validating, volatile, and hostile) were applied to study the participants' conflict styles. Multinomial logistic regression was then conducted on a sample of 25,511 participants, testing the relationships between the conflict styles of parents, their adult children's conflict styles, and their adult children's partners' conflict styles. All of the perceived parental conflict styles were linked to the same conflict styles in adult children. However, for adult children and their partners, the patterns were mixed. Whereas having validating parents predicted having validating partners, having avoidant or hostile parents predicted having hostile partners. The results suggest the possibility of the intergenerational transmission of conflict styles between parents and their adult children as well as contributing to the established research on assortative mating in that individuals may be more likely to select partners who are similar to them in terms of their approaches to conflict. The results of this study have important implications for intervening early in families with less functional conflict styles.
\end{abstract}

Keywords Conflict styles - Intergenerational transmission • Hostility

Dean M. Busby

dean_busby@byu.edu

1 School of Family Life, Brigham Young University, 2086 JFSB, Provo, Utah 84602, USA
The management of conflict when communicating is one of the primary processes that determine whether a relationship will be stable and satisfying (Stanley et al. 2002). Although there are several studies on conflict resolution and how it influences romantic relationship outcomes (e.g., Busby and Holman 2009; Gottman 1993; Holman and Jarvis 2003, Sierau and Herzberg 2012), the genesis of these conflict styles remains to be studied. It may be that an adult's conflict style emerges in response to parental conflict styles that were experienced as a child.

According to Gottman (1993; 1994), people communicate and sort through disagreements with distinct and different styles, and these styles have an important influence on the quality and duration of relationships. Gottman categorized these styles into the following types: avoidant, validating, volatile, and hostile. Avoidant individuals focus more on emphasizing common ground rather than differences. Instead of actively arguing or debating issues, they consider waiting and letting things work out on their own as a preferred way to solve problems. Avoidant individuals usually do not display a lot of positive or negative emotions and they have little or no intention of persuading others.

Validating individuals do engage in discussions about conflictual issues, but their conversations are usually reasonably calm. They value the skills of listening to and understanding others' opinions. They also focus on providing empathy and understanding to others. This does not mean that validators always agree with others. In fact, they can be very firm about their own perspectives when they do debate or argue. However, they emphasize and appreciate the process of validating while communicating. In contrast volatile individuals are characterized by both their positive and negative affect. Compared with validating individuals, they are more likely to debate issues hotly and with vigor. They laugh and smile more, but they also argue intensely 
with strong desires to persuade the other person. As part of their agenda to persuade others, they listen less and assent less than validators.

Hostile individuals engage in a high volume of conflict that is coupled with criticism and defensiveness. They are more likely than those with the other conflict styles to attack others by pointing out or blaming the other person's false motivations or behaviors. Their negative feelings escalate quickly through their judgmental tone of voice or facial expression, which oftentimes results in the other person's counter-attack. Three of these four conflict styles can be functional and are often a part of healthy relationships, but the hostile style is not associated with stable or satisfying relationships (Gottman 1999). In more recent research the validating style has received stronger empirical support for its association with positive relationship outcomes than the avoidant or volatile styles, though all three of these styles are more strongly associated with positive outcomes than the hostile style (Busby and Holman 2009; Holman and Jarvis 2003). While it is certainly possible that individuals have more than one conflict style depending on the circumstances and the relationship, research on the Gottman styles is about studying the usual approach to conflictual situations in enduring relationships. This conflict is not the daily communication couples experience, rather it is when there is a clear instance of a significant disagreement between partners (Gottman 1994; Holman and Jarvis 2003).

Gottman's research and findings on conflict typologies are helpful in measuring and understanding individual conflict styles. However, if we are interested in finding out why an individual develops certain conflict styles, one way to understand this is to examine the possible connection between the individual and her/his parent's conflict styles. While we were not able to locate studies that specifically showed the intergenerational transmission of parental conflict styles to their children, we did find studies that show that the way parents handle communication in their families is linked to their children's communication, emotional reactivity, and attempts at conflict resolution. For example, Brown et al. (2007) studied children who acknowledged interparental conflicts in their homes. They reported that for those children who perceived their mothers to be more open to discussions, these children also appeared to be more open to discussions themselves. Topham et al. (2005) studied the influence of the family-of-origin on adult children who were married. They discovered that for wives, their family-of-origin atmosphere and experiences were negatively related to both the husbands and the wives' hostile marital conflicts. Hence, for those who had more positive family-of-origin experiences, they appeared to be less hostile in conflictual situations. However, for those who had negative experiences, they demonstrated more hostility in their marital conflict. Similar results were also shared by Gardner et al. (2007). Their study showed that adult children who experienced negative family-of-origin experiences also demonstrated more negative emotional reactivity (such as being irritated more easily), which then lead to poor conflict management. So for these individuals their conflict management skills were influenced by the household they grew up in.

Although the literature does include some links between parental communication patterns and their adult children's own behaviors when communicating (e.g., Halberstadt 1986), from what we could identify, there was still little literature that directly studied the connection between parental conflict styles and their adult children's conflict styles. While there may be many factors that contribute to the development of a particular conflict style of an individual, one obvious influence may be their parents' approach to conflict. From a theoretical perspective, Social Learning Theory would propose that one of the ways individuals learn is through observing others. Observation allows individuals to witness other people undergo pleasant or painful experiences after behaving in a certain way. Through the process of observation, imitation and reinforcement, individuals learn and establish the pattern through which they believe certain actions bring about desired outcomes (Bandura 1971). Based on Social Learning Theory and the concept of observation and reinforcement, we might expect that the conflict style of parents would influence the development of conflict styles in children. This means that children imitate, adapt or adjust the behavioral patterns which they observed from their parents. This could imply that when we try to understand the connection between the conflict styles of parents and that of their children, it is important for us to understand the perception of the children about conflict styles even when they are adults. If one of the major processes for the development of children's adult behavioral patterns is through observing and learning, then their experiences as children and their perceptions of what happened could alter what they choose to imitate or disregard.

In addition to the potential link between adult children's conflict styles and their parents' conflict styles, in this study we ask another important and interesting question: are there connections between the adult children's parental conflict styles and adult children's partners' conflict styles? While there are even fewer studies that explored this particular idea, some researchers have documented different aspects of parental influences on adult children's mate selection. For instance, Geher (2000) studied adult children's perception of their parents' and romantic partners' personality traits (such as openness, conscientiousness, extraversion, agreeableness, and neuroticism) and attachment styles. The results showed that: (1) all of the correlations between adult children's perceived parental characteristics and partner characteristics were statistically significant; (2) there were both positive correlations (such as with openness) and negative 
correlations (such as with neuroticism) between adult children's parents and partners. Other than Geher's research findings, there is additional literature on assortative mating that sheds some light on parental influences on mate selection. For example, researchers have found that individuals are often attracted to mates that share similar traits that the individuals' parents have, including but not limited to physical, social, economic, emotional and relational similarities (e.g., Bereczkei et al. 2003; Little et al. 2003; Zietsch et al. 2011). The research is mixed in this area with some of it showing personality and attitudinal characteristics are central to assortative mating that may or may not come from parental influences (Luo and Klohnen 2005; Watson et al. 2014) while other research shows that it is convergence of interacting styles after mates are selected that underlie significant aspects of partner similarity (Ask et al. 2013). Regardless, both types of findings suggest the lack of research that directly explores the influence of parental conflict approaches on the mate selection of their adult children.

Similar to the reasoning of our first research interest, we find Social Learning Theory to be appropriate in explaining the influence of parental characteristics on mate selection choices. As pointed out by Bandura (1971), individuals have three important processes that assist them in learning; these are vicarious, symbolic, and self-regulatory processes. Through these three primary processes, individuals would not need to personally experience an outcome in order to learn the lesson, rather, they could learn by observing others, symbolically working out a solution, and foreseeing problems. Applying social learning theory, we suspect that adult children could learn from their parents' interactions about what desired and undesired or normal and abnormal conflict styles would be in couple relationships, and later on these experiences would contribute to their preferences regarding how potential partners should approach conflict. These expectations could influence the selection of particular partners as being compatible or desirable.

The focus of this study is to find out if there is a connection between parents' and their adult children's conflict styles, as well as between the parents' conflict styles and the conflict styles of their adult children's romantic partners, as perceived by the adult children. While it would certainly be ideal to study individuals and their parents during early development and then explore if there is a longitudinal connection between parental and child conflict styles when children became adults, an important first step is to explore whether adult children perceive there to be a link between their ratings of parental conflict styles and their own, as well as with the conflict styles of their partners. These perceptions can then become a bridge to understanding and intervening in conflict experiences that can be frustrating and damaging or that can facilitate positive conflict management in current relationships.

\section{Method}

\section{Participants}

The sample for this study was drawn from the entire population of respondents who completed the Relationship Evaluation Questionnaire (RELATE, Busby et al. 2001) between 2003 and 2014. In order to answer the research questions of this study, only participants who met the following criteria were selected into the current dataset from the original pool of participants: (1) Participants had to have 2 parents, whether it be biological, adopted, or step father/ mother. We had this criterion because we were specifically interested in finding out the joint influence of both fathers and mothers' conflicts styles. (2) Participants had to be in stable romantic relationships (either dating, engaged, or married) for at least 6 months.

The criteria resulted in a final sample of 25,511 individuals. Thirty-nine percent (9841) of them were males and $61 \%(15,670)$ were females. The age range for our sample was 18 to 79 , with a mean age 32.1 for males and 29.5 for females. In terms of participant race and ethnicity, $81 \%$ were Caucasian, 5\% African American, 4\% Asian, 4\% Latino, and 6\% listed "other." Regarding their education, $39 \%$ had not obtained a college degree; $31 \%$ had an associates or bachelors degree; $30 \%$ had a graduate degree. Twenty-six percent of them identified themselves as Protestant (including Methodist, Lutheran, Episcopalian, Baptist, etc.), 26\% were Latter-Day Saints (Mormons), $18 \%$ were non-religious, $15 \%$ were Catholic, and the remaining $15 \%$ were other religions including Jewish, Buddhist, Islamic, Hindu, Sikh, Jehovah's Witnesses, and Unitarian Universalists. As far as relationship status, $34 \%$ were married, $39 \%$ were engaged, and $27 \%$ were in a serious dating relationship.

\section{Procedure}

RELATE is a questionnaire designed to evaluate multiple dimensions of couple relationships. Respondents completed RELATE online after being introduced to the instrument through a variety of settings, including university classes, workshops for couples, and web advertisement.

\section{Measures}

\section{Conflict styles}

The primary measurement we used in this study was conflict styles. We used this measurement to understand the adult children's perception of both their parents', their romantic partners', and their own conflict styles. This measurement was developed from the original Gottman 
conflict styles, which were generated from his observational coding of couple interactions (Gottman 1994). Gottman then developed some questions to measure the different conflict styles in several of his books (Gottman 1994, 1999), although these items from his books were not evaluated or used by scholars at the time. More recently, several researchers have taken Gottman's questions and developed a questionnaire-based approach and shown it to be predictive of relationship outcomes as expected (Busby and Holman 2009; Holman and Jarvis 2003). The conflict styles measured in the current study came from Holman and Jarvis' study (2003). As a single item measure typical reliability data is not available nor is construct validity information. However, these previous studies have indicated that this measure has a degree of predictive validity.

The following is a detailed description of what was asked of the participants, using the mother as an example: "Below are four common ways of handling disagreements or conflict in relationships. Please choose the ONE that best describes your mother:

1. My mother avoided conflict. She didn't think there was much to be gained from getting openly angry with others. In fact, to her a lot of talking about emotions and difficult issues seemed to make matters worse. She thought that if people would just relax, problems would have a way of working themselves out.

2. My mother discussed difficult issues, but it was important to her to display a lot of self-control and to remain calm. She preferred to let others know that their opinions and emotions were valued even if they were different than hers. When arguing, she tried to spend a lot of time validating others as well as trying to find a compromise.

3. My mother debated and argued about issues until they were resolved. Arguing openly and strongly didn't bother her because this was how she felt differences were resolved. Although sometimes her arguing was intense, that was okay because she tried to balance this with kind and loving expressions. She thought that her passion and zest actually lead to better relationships with lots of intensity, making up, laughing, and affection.

4. My mother could get pretty upset when she argued. When she was upset at times she insulted others by using something like sarcasm or put downs. During intense discussions she found it was difficult to listen to what others were saying because she was trying to make her point. Sometimes she had intensely negative feelings toward others when there was a conflict."

The same sets of questions were asked of the participants regarding their fathers, themselves, and their partners. All wording was the same except for the person described. From these variables, participants selected what they considered to be the most appropriate option for themselves, their mothers, their fathers, and their partners. These questions were separated on the questionnaire by many other questions so as to reduce response bias and direct comparison between self, partner, and both parents.

\section{Control variables}

We included several control variables, because past studies showed that demographic variables such as level of education, religious belief, relationship status, and length of relationship could influence family communication dynamics (e.g., Brelsford 2013; Chi 2013; Cohan and Kleinbaum 2002; Croucher et al. 2011; Sabatelli et al. 1982; Skinner et al. 2002; Stanley et al. 2002). Although there were not articles that discussed the direct relationships between these variables and the development of certain conflict styles, since these variables do influence the individuals' communication, we included them to ensure that our study outcomes would not be confounded by these variables.

Education We included the participants' level of education as a control variable. We asked the participants to select from a list of the following options regarding their level of education: less than high school, high school equivalency, high school diploma, some college, associate's degree, bachelor's degree, graduate or professional degree.

Religion and religiosity We assessed the participants' religious background and religiosity by asking them two questions. The first question was to choose from a dropdown list the religion they belonged to. The options included Catholic, Protestant, Jewish, Islamic, Latter-day Saint, Buddhist, Hindu, Sikh, Other, and None. The participants then answered another question on religiosity by evaluating how often they attended religious services, to which they chose one of the five options: "weekly", "at least monthly", "several times a year", "once or twice a year", and "never".

Relationship status Relationship status was another control variable we used. We asked the participants to select from a drop down list regarding their current marital status. As previously explained for this study, only participants that were in an exclusive dating relationship, engaged, or married were included in the current sample.

Length of relationship Our last control variable was the length of the participants' current romantic relationship. They were asked to identify how long they had been in the current romantic relationships with their partners. While age 
is another control variable that might commonly be used, it was strongly associated with relationship length so it was not selected for this study.

\section{Data Analyses}

All analyses were performed in IBM SPSS Statistics 21 and StataSE 14.

\section{Preliminary analyses}

For the preliminary analyses, we conducted Cross Tabulations to find out if there was a relationship between perceived parental conflict styles and the adult children's (and their romantic partners') conflict styles. Statistically significant Chi-square results would establish the dependency between these variables and suggest the need for further investigation of the actual relationships. In this study, we used three-way cross tabulations so that we could examine the joint influence of fathers and mothers' conflict styles at the same time. Also, since the Chi-square test is sensitive to large sample sizes, as part of the analysis, we examined the effect size statistics.

\section{Multinomial logistic regression}

The Chi-square and effect size statistics revealed that there was a relationship between perceived parental conflict styles and the conflict styles of their adult children and their romantic partners (see Table 1). (We will discuss the detailed outcomes in the result section.) In order to further investigate the nature of these relationships, we conducted multinomial logistic regression. Since our conflict style variables were nominal and couldn't be effectively ranked in order, multinomial logistic regression was an appropriate option. It provided a way to help us understand the level of influence of different perceived parental conflict styles by comparing the odds of each group to the reference group.

We ended up with 4 separate models. All models included father conflict styles and mother conflict styles as independent variables, and education, religion, level of religiosity, relationship status, and length of relationship as control variables. Each of the 4 models had a different dependent variable: male adult children conflict styles, female adult children conflict styles, male adult children's partners' conflict styles, and female adult children's partners' conflict styles.

Unlike linear regression models which would allow us to see and compare the strength of every independent variable side by side in the model, with multinomial logistic regression models it is necessary to leave out one group as
Table 1 Pearson chi-square and effect-size testing significant relationships between parental and adult children/partners' conflict styles

\begin{tabular}{|c|c|c|c|}
\hline & $X^{2}$ & df & Phi-Statistic \\
\hline \multicolumn{4}{|c|}{ Between male adult children and parents } \\
\hline Male adult children avoidant & $51.16^{*}$ & 9 & $.20 *$ \\
\hline Male adult children validating & $256.61 *$ & 9 & $.25 *$ \\
\hline Male adult children volatile & $149.58 *$ & 9 & $.26^{*}$ \\
\hline Male adult children hostile & $46.07 *$ & 9 & $.23 *$ \\
\hline \multicolumn{4}{|c|}{ Between female adult children and parents } \\
\hline Female adult children avoidant & $66.03 *$ & 9 & $.23 *$ \\
\hline Female adult children validating & $449.16^{*}$ & 9 & $.29 *$ \\
\hline Female adult children volatile & $334.14 *$ & 9 & $.27 *$ \\
\hline Female adult children hostile & $117.68^{*}$ & 9 & $.23 *$ \\
\hline \multicolumn{4}{|c|}{ Between male adult children's parents and partners } \\
\hline Males' partners avoidant & $64.43 *$ & 9 & $.22 *$ \\
\hline Males' partners validating & $243.70 *$ & 9 & $.27 *$ \\
\hline Males' partners volatile & $107.17 *$ & 9 & $.23 *$ \\
\hline Males' partners hostile & $86.64 *$ & 9 & $.23 *$ \\
\hline \multicolumn{4}{|c|}{ Between female adult children's parents and partners } \\
\hline Females' partners avoidant & $222.37 *$ & 9 & $.25 *$ \\
\hline Females' partners validating & $395.65 *$ & 9 & $.28 *$ \\
\hline Females' partners volatile & $155.13^{*}$ & 9 & $.24 *$ \\
\hline Females' partners hostile & $117.68 *$ & 9 & $.22 *$ \\
\hline
\end{tabular}

Note: $N=9841$ for males and 15,670 for females

$* p<.01$

the reference group (Hoffmann 2004). In this study, our primary reference group was the validating group. The choice of this group was based on both conceptual and methodological reasons. Conceptually, among all four styles, the validating group was characterized by its neutrality in terms of demonstrating negativity during a conflict situation. Therefore, we considered the validating group to be an appropriate reference group. Methodologically, the reference group for multinomial logistic regression would preferably be the group with the largest sample size. Since in our sample we had the most people in the validating group, it became a natural choice.

However, the shortcoming associated with the parental validating group being the reference group is that it would not be possible to compare the validating groups with the other groups on the adult children and their partners conflict styles. As a result, after we used the validating group as a reference group, we conducted a secondary analysis using the hostile group as the reference group. The hostile group was chosen as reference for the secondary analysis because it has been characterized as a nonregulated or nonfunctional group by Gottman $(1993,1994)$ with the most negativity during conflict management. Switching the reference group from validating to hostile allowed us to compare the effects 
of all groups while meeting the statistical requirements of the multinomial logistic regression models.

\section{Results}

Tables 1 to 3 show the results of the cross tabulation, Chisquare, and effect size tests. The effect size statistics (Phi coefficients) ranged from .20 to .29 , indicating that the relationships between perceived parental conflict styles and the adult children's conflict styles were significant and had a moderate effect size, and that these relationships were not likely due to only the large sample size. Chi-square information confirmed that there were significant relationships between the joint influences of perceived parental conflict styles and their adult children's conflict styles, as well as between the parental and partner styles. Table 1 provides a detailed list of Phi and Chi-square values (all significant at $\mathrm{p}<.01$ level). These preliminary analyses indicated that further analyses needed to be done to investigate more thoroughly the relationship among the parental conflict styles, adult children conflict styles, and the adult children's partners' conflict styles. We then moved on to the multinomial logistic regression analyses.
For the male adult children's model, model fit information showed that the Likelihood Ratio Chi-square (comparing the null model and the hypothesized model) with 69 degrees of freedom was 1014.52, $p<0.01$. All together, the results indicated that the hypothesized model that included perceived parental conflict style predictors was significantly better than the intercept-only model (or null model). In other words, it was appropriate to use perceived parental conflict styles as independent variables in this model to predict male adult children's conflict styles. Likewise, model fit information showed that the other three models were appropriate. For the female adult children model the Chi-square was $1290.10, \mathrm{df}=69, \mathrm{p}<0.01$. For male adult children's partner model the Chi-square was $645.46, \mathrm{df}=$ $69, \mathrm{p}<0.01$. For the female adult children's partner model the Chi-square was 1249.82, $\mathrm{df}=69, \mathrm{p}<0.01$.

\section{Using Relative Risk Ratio to Understand Conflict Styles}

After evaluating the model fit, we looked into each conflict style of the adult children and their partners. Tables 4 through 7 provide detailed information of how each perceived parental conflict style predicted the adult children's and their partners' conflict styles. When examining the
Table 2 Cross tabulation of parental and adult children conflict styles

\begin{tabular}{|c|c|c|c|c|c|c|c|c|}
\hline & \multicolumn{2}{|c|}{ Avoidant } & \multicolumn{2}{|c|}{ Validating } & \multicolumn{2}{|c|}{ Volatile } & \multicolumn{2}{|l|}{ Hostile } \\
\hline & Males & Females & Males & Females & Males & Females & Males & Females \\
\hline \multicolumn{9}{|l|}{ Father avoidant, and } \\
\hline Mother avoidant & $11.3 \%$ & $8.8 \%$ & $4.7 \%$ & $4.6 \%$ & $2.6 \%$ & $3.0 \%$ & $4.3 \%$ & $4.1 \%$ \\
\hline Mother validating & $8.6 \%$ & $7.5 \%$ & $7.4 \%$ & $6.0 \%$ & $4.9 \%$ & $3.6 \%$ & $5.7 \%$ & $4.1 \%$ \\
\hline Mother volatile & $7.0 \%$ & $6.2 \%$ & $4.8 \%$ & $4.8 \%$ & $4.9 \%$ & $5.3 \%$ & $4.4 \%$ & $4.0 \%$ \\
\hline Mother hostile & $8.3 \%$ & $11.6 \%$ & $6.1 \%$ & $9.6 \%$ & $6.7 \%$ & $10.9 \%$ & $9.1 \%$ & $13.0 \%$ \\
\hline \multicolumn{9}{|c|}{ Father validating, and } \\
\hline Mother avoidant & $5.8 \%$ & $5.4 \%$ & $5.0 \%$ & $3.9 \%$ & $3.2 \%$ & $2.3 \%$ & $2.6 \%$ & $2.8 \%$ \\
\hline Mother validating & $9.4 \%$ & $6.8 \%$ & $19.4 \%$ & $13.9 \%$ & $7.9 \%$ & $5.4 \%$ & $5.5 \%$ & $5.1 \%$ \\
\hline Mother volatile & $4.7 \%$ & $4.5 \%$ & $7.2 \%$ & $6.4 \%$ & $7.1 \%$ & $6.1 \%$ & $4.7 \%$ & $4.3 \%$ \\
\hline Mother hostile & $3.3 \%$ & $5.3 \%$ & $4.6 \%$ & $5.9 \%$ & $4.1 \%$ & $6.2 \%$ & $5.0 \%$ & $5.9 \%$ \\
\hline \multicolumn{9}{|l|}{ Father volatile, and } \\
\hline Mother avoidant & $4.4 \%$ & $3.2 \%$ & $3.2 \%$ & $2.9 \%$ & $4.0 \%$ & $3.7 \%$ & $3.3 \%$ & $3.2 \%$ \\
\hline Mother validating & $5.7 \%$ & $4.6 \%$ & $8.7 \%$ & $6.2 \%$ & $12.0 \%$ & $6.5 \%$ & $5.3 \%$ & $3.1 \%$ \\
\hline Mother volatile & $3.2 \%$ & $3.4 \%$ & $4.4 \%$ & $2.8 \%$ & $8.4 \%$ & $4.9 \%$ & $4.8 \%$ & $2.3 \%$ \\
\hline Mother hostile & $2.0 \%$ & $2.0 \%$ & $1.8 \%$ & $2.2 \%$ & $3.3 \%$ & $3.8 \%$ & $2.6 \%$ & $3.9 \%$ \\
\hline \multicolumn{9}{|l|}{ Father hostile, and } \\
\hline Mother avoidant & $10.8 \%$ & $12.5 \%$ & $6.6 \%$ & $9.8 \%$ & $7.7 \%$ & $10.7 \%$ & $12.9 \%$ & $13.4 \%$ \\
\hline Mother validating & $6.1 \%$ & $6.6 \%$ & $8.0 \%$ & $9.2 \%$ & $8.2 \%$ & $8.8 \%$ & $11.5 \%$ & $8.9 \%$ \\
\hline Mother volatile & $4.2 \%$ & $3.7 \%$ & $3.5 \%$ & $4.7 \%$ & $7.1 \%$ & $7.5 \%$ & $6.7 \%$ & $6.3 \%$ \\
\hline Mother hostile & $5.2 \%$ & $7.9 \%$ & $4.6 \%$ & $7.1 \%$ & $7.9 \%$ & $11.3 \%$ & $11.6 \%$ & $15.6 \%$ \\
\hline
\end{tabular}

Note: $N=9841$ for males and 15,670 for females 
Table 3 Cross tabulation of parental and adult children's partners' conflict styles

\begin{tabular}{|c|c|c|c|c|c|c|c|c|}
\hline & \multicolumn{2}{|l|}{ Avoidant } & \multicolumn{2}{|c|}{ Validating } & \multicolumn{2}{|l|}{ Volatile } & \multicolumn{2}{|l|}{ Hostile } \\
\hline & $\begin{array}{l}\text { Males' } \\
\text { Partners }\end{array}$ & $\begin{array}{l}\text { Females' } \\
\text { Partners }\end{array}$ & $\begin{array}{l}\text { Males' } \\
\text { Partners }\end{array}$ & $\begin{array}{l}\text { Females' } \\
\text { Partners }\end{array}$ & $\begin{array}{l}\text { Males' } \\
\text { Partners }\end{array}$ & $\begin{array}{l}\text { Females' } \\
\text { Partners }\end{array}$ & $\begin{array}{l}\text { Males' } \\
\text { Partners }\end{array}$ & $\begin{array}{l}\text { Females' } \\
\text { Partners }\end{array}$ \\
\hline \multicolumn{9}{|l|}{ Father avoidant, and } \\
\hline Mother avoidant & $5.6 \%$ & $4.8 \%$ & $4.8 \%$ & $3.9 \%$ & $4.5 \%$ & $4.1 \%$ & $5.7 \%$ & $5.1 \%$ \\
\hline Mother validating & $6.3 \%$ & $4.9 \%$ & $6.9 \%$ & $5.0 \%$ & $5.8 \%$ & $5.2 \%$ & $7.9 \%$ & $5.0 \%$ \\
\hline Mother volatile & $5.6 \%$ & $5.7 \%$ & $4.9 \%$ & $4.6 \%$ & $5.7 \%$ & $4.5 \%$ & $4.7 \%$ & $4.9 \%$ \\
\hline Mother hostile & $6.9 \%$ & $12.3 \%$ & $5.5 \%$ & $9.8 \%$ & $7.0 \%$ & $9.7 \%$ & $9.6 \%$ & $12.0 \%$ \\
\hline \multicolumn{9}{|c|}{ Father Validating, and } \\
\hline Mother avoidant & $5.3 \%$ & $2.3 \%$ & $4.4 \%$ & $3.7 \%$ & $4.5 \%$ & $3.5 \%$ & $3.8 \%$ & $3.8 \%$ \\
\hline Mother validating & $10.2 \%$ & $5.7 \%$ & $18.7 \%$ & $12.9 \%$ & $11.1 \%$ & $8.2 \%$ & $7.9 \%$ & $6.1 \%$ \\
\hline Mother volatile & $6.4 \%$ & $4.4 \%$ & $7.1 \%$ & $7.0 \%$ & $6.8 \%$ & $5.7 \%$ & $5.1 \%$ & $4.9 \%$ \\
\hline Mother hostile & $4.6 \%$ & $5.5 \%$ & $3.7 \%$ & $6.2 \%$ & $4.4 \%$ & $5.8 \%$ & $5.3 \%$ & $6.4 \%$ \\
\hline \multicolumn{9}{|l|}{ Father volatile, and } \\
\hline Mother avoidant & $3.8 \%$ & $3.2 \%$ & $3.4 \%$ & $3.1 \%$ & $3.9 \%$ & $3.8 \%$ & $3.7 \%$ & $3.2 \%$ \\
\hline Mother validating & $8.2 \%$ & $4.9 \%$ & $9.9 \%$ & $6.6 \%$ & $8.8 \%$ & $6.4 \%$ & $7.0 \%$ & $3.8 \%$ \\
\hline Mother volatile & $5.5 \%$ & $3.1 \%$ & $4.9 \%$ & $3.5 \%$ & $6.6 \%$ & $4.6 \%$ & $4.7 \%$ & $2.9 \%$ \\
\hline Mother hostile & $2.8 \%$ & $3.6 \%$ & $1.9 \%$ & $2.6 \%$ & $2.3 \%$ & $3.2 \%$ & $2.5 \%$ & $2.6 \%$ \\
\hline \multicolumn{9}{|l|}{ Father hostile, and } \\
\hline Mother avoidant & $8.9 \%$ & $12.9 \%$ & $6.5 \%$ & $8.8 \%$ & $8.2 \%$ & $10.9 \%$ & $10.7 \%$ & $12.7 \%$ \\
\hline Mother validating & $7.6 \%$ & $8.2 \%$ & $8.0 \%$ & $8.9 \%$ & $8.0 \%$ & $9.4 \%$ & $8.7 \%$ & $8.7 \%$ \\
\hline Mother volatile & $4.7 \%$ & $6.2 \%$ & $4.2 \%$ & $5.5 \%$ & $6.6 \%$ & $6.1 \%$ & $4.6 \%$ & $5.4 \%$ \\
\hline Mother hostile & $7.6 \%$ & $12.3 \%$ & $5.2 \%$ & $7.9 \%$ & $5.8 \%$ & $8.9 \%$ & $8.1 \%$ & $12.5 \%$ \\
\hline
\end{tabular}

Note: $N=9841$ for males and 15,670 for females

Table 4 Multinomial logistic regression testing parental conflict styles on male adult children conflict styles

\begin{tabular}{|c|c|c|c|c|c|c|c|c|}
\hline & \multicolumn{2}{|l|}{ Avoidant } & \multicolumn{2}{|l|}{ Volatile } & \multicolumn{2}{|l|}{ Hostile } & \multicolumn{2}{|l|}{ Validating $^{\mathrm{a}}$} \\
\hline & $\beta(\mathrm{SE})$ & $\operatorname{Exp}(\beta)$ & $\beta$ (SE) & $\operatorname{Exp}(\beta)$ & $\beta$ (SE) & $\operatorname{Exp}(\beta)$ & $\beta(\mathrm{SE})$ & $\operatorname{Exp}(\beta)$ \\
\hline \multicolumn{9}{|l|}{ Father styles } \\
\hline Avoidant & $.75(.09)^{* *}$ & 2.12 & $.16(.08)$ & 1.17 & $.38(.13)^{* *}$ & 1.46 & $.73(.11)^{* *}$ & 2.08 \\
\hline Volatile & $.17(.11)$ & 1.19 & $.88(.08)^{* *}$ & 2.41 & $.55(.13)^{* *}$ & 1.73 & $.57(.12)^{* *}$ & 1.77 \\
\hline Hostile & $.42(.10)^{* *}$ & 1.52 & $.74(.08)^{* *}$ & 2.10 & $1.11(.11)^{* *}$ & 3.03 & & \\
\hline Validating $^{\mathrm{a}}$ & & & & & & & $1.11(.11)^{* *}$ & 3.03 \\
\hline \multicolumn{9}{|l|}{ Mother styles } \\
\hline Avoidant & $.72(.09)^{* *}$ & 2.05 & $.04(.08)$ & 1.27 & $.23(.12)$ & 1.26 & $.53(.12)^{* *}$ & 1.70 \\
\hline Volatile & $.30(.10)^{* *}$ & 1.35 & $.55(.07)^{* *}$ & 1.73 & $.49(.12)^{* *}$ & 1.63 & $.26(.12)^{*}$ & 1.30 \\
\hline Hostile & $.33(.10)^{* *}$ & 1.39 & $.49(.08)^{* *}$ & 1.63 & $.76(.11)^{* *}$ & 2.14 & & \\
\hline Validating $^{\mathrm{a}}$ & & & & & & & $.76(.11)^{* *}$ & 2.14 \\
\hline Intercept & $-1.56(.19)^{* *}$ & & $-1.16(.15)^{* *}$ & & $-2.34(.22)^{* *}$ & & $.47(.22)^{*}$ & \\
\hline
\end{tabular}

Note: $N=9841$. The cell where the parental conflict style and the adult children's conflict style were validating was the reference group when testing the avoidant, volatile, and hostile styles

${ }^{a}$ When testing the validating group, the hostile conflict style was used as a temporary reference group

$* p<.05, * * p<.01$

findings in this section, it is important to remember that in multinomial logistic regression we compare the outcomes between groups based on their relationships to the reference group. In all instances the reference group was the cell where the parental conflict group and the adult child's conflict group were validating or hostile as indicated in the 
tables. Also, all results were reported with level of education, religion, religiosity, relationship status and relationship length controlled for.

\section{Predicting Adult Children's Avoidant Conflict Style}

We first looked at the avoidant adult children (see Table 4). When using the validating cell for both parents and child as the reference group, the likelihood of avoidant fathers having an adult child who was avoidant was 2.12 times higher than the likelihood of them having children with other types of conflict styles. Also for avoidant mothers (again using validating as the reference group), the relative risk ratio (2.05) showed that they were most likely to have avoidant children rather than other types of conflict. The same pattern applied to female adult children (see Table 5). When using validating as the reference group, with every one unit increase in the father and the mother's avoidant conflict styles, there was 75 to $80 \%$ increase in the adult children's likelihood of being avoidant as well. Thus we can see that the best predictor for both male and female adult children having an avoidant style was when they had avoidant fathers and/or mothers.

\section{Predicting Adult Children's Hostile and Volatile Conflict Styles}

The other significant connection was between hostile fathers and hostile adult children. Again using the validating cell as the reference group, when fathers were hostile they were significantly more likely to have a child with hostile conflict styles (relative risk ratio $=3.03$ ). The results were similar for hostile mothers and their adult male children (relative risk ratio $=2.14$ ). For females, when fathers/mothers were hostile they were more than two times as likely to have hostile adult female children in comparison to other groups. These results for both male and female adult children show that there is a strong connection between the parents' hostile conflict styles and the adult children's conflict styles. Likewise, the very same pattern emerged for both male and female adult children and the volatile conflict style. When they had volatile parents (whether it was fathers or mothers), the likelihood of their being volatile was the highest in the model.

\section{Predicting the Partners' Hostile Style}

We also looked at the adult children's partners' conflict styles. The results were interesting (see Table 6 and 7). For male adult children, when their fathers and mothers were avoidant, there was more than a 50\% higher likelihood they would have hostile partners (with the validating cell as the reference group). It was the same for females. When the females' parents were avoidant, they had the highest likelihood in the model of having hostile partners (1.88 for when they had avoidant fathers and 1.57 for when they had avoidant mothers).

In addition, adult children's parents' hostile conflict style predicted the adult children's partners' hostile style. With the validating cell as reference in the model, the best predictor for both male and female adult children having hostile partners was when their parents were hostile (1.75 for hostile fathers and 1.80 for hostile mothers). For female adult children, the risk ratios of their having hostile partners

Table 5 Multinomial logistic regression testing parental conflict styles on female adult children conflict styles

\begin{tabular}{|c|c|c|c|c|c|c|c|c|}
\hline & \multicolumn{2}{|l|}{ Avoidant } & \multicolumn{2}{|l|}{ Volatile } & \multicolumn{2}{|l|}{ Hostile } & \multicolumn{2}{|l|}{ Validating $^{\mathrm{a}}$} \\
\hline & $\beta(\mathrm{SE})$ & $\operatorname{Exp}(\beta)$ & $\beta(\mathrm{SE})$ & $\operatorname{Exp}(\beta)$ & $\beta(\mathrm{SE})$ & $\operatorname{Exp}(\beta)$ & $\beta(\mathrm{SE})$ & $\operatorname{Exp}(\beta)$ \\
\hline \multicolumn{9}{|l|}{ Father styles } \\
\hline Avoidant & $.56(.09)^{* *}$ & 1.75 & $.14(.06)^{*}$ & 1.15 & $.25(.08)^{* *}$ & 1.28 & $.49(.07)^{* *}$ & 1.63 \\
\hline Volatile & $.25(.11)^{*}$ & 1.28 & $.72(.07)^{* *}$ & 2.05 & $.39(.09)^{* *}$ & 1.48 & $.34(.09)^{* *}$ & 1.40 \\
\hline Hostile & $.27(.09)^{* *}$ & 1.31 & $.59(.06)^{* *}$ & 1.80 & $.73(.07)^{* *}$ & 2.08 & & \\
\hline Validating $^{\mathrm{a}}$ & & & & & & & $.73(.07)^{* *}$ & 2.08 \\
\hline \multicolumn{9}{|l|}{ Mother styles } \\
\hline Avoidant & $.59(.09)^{* *}$ & 1.80 & $.18(.06)^{* *}$ & 1.20 & $.37(.08)^{* *}$ & 1.45 & $.49(.08)^{* *}$ & 1.63 \\
\hline Volatile & $.28(.10)^{* *}$ & 1.32 & $.63(.06)^{* *}$ & 1.88 & $.44(.08)^{* *}$ & 1.55 & $.42(.08)^{* *}$ & 1.52 \\
\hline Hostile & $.31(.09)^{* *}$ & 1.36 & $.62(.06)^{* *}$ & 1.86 & $.86(.07)^{* *}$ & 2.36 & & \\
\hline Validating $^{\mathrm{a}}$ & & & & & & & $.86(.07)^{* *}$ & 2.36 \\
\hline Intercept & $-1.78(.19)^{* *}$ & & $-.70(.12)^{* *}$ & & $-1.67(.15)^{* *}$ & & $.08(.15)$ & \\
\hline
\end{tabular}

Note: $N=15,670$. The cell where the parental conflict style and the adult children's conflict style were validating was the reference group when testing the avoidant, volatile, and hostile styles

${ }^{a}$ When testing the validating group, the hostile style was used as a temporary reference group

$* p<.05, * * p<.01$ 
Table 6 Multinomial logistic regression testing parental conflict styles on conflict styles of male adult children's partners

\begin{tabular}{|c|c|c|c|c|c|c|c|c|}
\hline & \multicolumn{2}{|l|}{ Avoidant } & \multicolumn{2}{|l|}{ Volatile } & \multicolumn{2}{|l|}{ Hostile } & \multicolumn{2}{|l|}{ Validating $^{\mathrm{a}}$} \\
\hline & $\beta(\mathrm{SE})$ & $\operatorname{Exp}(\beta)$ & $\beta(\mathrm{SE})$ & $\operatorname{Exp}(\beta)$ & $\beta(\mathrm{SE})$ & $\operatorname{Exp}(\beta)$ & $\beta$ (SE) & $\operatorname{Exp}(\beta)$ \\
\hline \multicolumn{9}{|l|}{ Father styles } \\
\hline Avoidant & $.28(.10)^{* *}$ & 1.32 & $.15(.08)$ & 1.16 & $.48(.09)^{* *}$ & 1.62 & $.08(.09)$ & 1.08 \\
\hline Volatile & $.27(.10)^{* *}$ & 1.31 & $.23(.09)^{* *}$ & 1.26 & $.29(.10)^{* *}$ & 1.34 & $.39(.10)^{* *}$ & 1.48 \\
\hline Hostile & $.42(.09)^{* *}$ & 1.52 & $.32(.09)^{* *}$ & 1.38 & $.56(.09)^{* *}$ & 1.75 & & \\
\hline Validating $^{\mathrm{a}}$ & & & & & & & $.56(.09)^{* *}$ & 1.75 \\
\hline \multicolumn{9}{|l|}{ Mother styles } \\
\hline Avoidant & $.42(.09)^{* *}$ & 1.52 & $.26(.08)^{* *}$ & 1.30 & $.27(.09)^{* *}$ & 1.31 & $.32(.10)^{* *}$ & 1.38 \\
\hline Volatile & $.32(.09)^{* *}$ & 1.38 & $.41(.08)^{* *}$ & 1.51 & $.20(.09)^{*}$ & 1.22 & $.39(.10)^{* *}$ & 1.48 \\
\hline Hostile & $.56(.10)^{* *}$ & 1.75 & $.36(.09)^{* * *}$ & 1.43 & $.59(.09)^{* *}$ & 1.80 & & \\
\hline Validating $^{\mathrm{a}}$ & & & & & & & $.59(.09)^{* *}$ & 1.80 \\
\hline Intercept & $-1.10(.18)^{* *}$ & & $-1.07(.16)^{* *}$ & & $-1.66(.18)^{* *}$ & & $.51(.18)^{* *}$ & \\
\hline
\end{tabular}

Note: $N=9841$. The cell where the parental conflict style and the adult children's partner's conflict style were validating was the reference group when testing the avoidant, volatile, and hostile styles

${ }^{a}$ When testing the validating group, the hostile style was used as a temporary reference group

$* p<.05, * * p<.01$

Table 7 Multinomial logistic regression testing parental conflict styles on conflict styles of female adult children's partners

\begin{tabular}{|c|c|c|c|c|c|c|c|c|}
\hline & \multicolumn{2}{|l|}{ Avoidant } & \multicolumn{2}{|l|}{ Volatile } & \multicolumn{2}{|l|}{ Hostile } & \multicolumn{2}{|l|}{ Validating $^{\mathrm{a}}$} \\
\hline & $\beta(\mathrm{SE})$ & $\operatorname{Exp}(\beta)$ & $\beta(\mathrm{SE})$ & $\operatorname{Exp}(\beta)$ & $\beta(\mathrm{SE})$ & $\operatorname{Exp}(\beta)$ & $\beta(\mathrm{SE})$ & $\operatorname{Exp}(\beta)$ \\
\hline \multicolumn{9}{|l|}{ Father styles } \\
\hline Avoidant & $.50(.07)^{* *}$ & 1.65 & $.17(.07)^{*}$ & 1.19 & $.23(.08)^{* *}$ & 1.26 & $.17(.07)^{*}$ & 1.19 \\
\hline Volatile & $.45(.08)^{* *}$ & 1.57 & $.35(.08)^{* *}$ & 1.42 & $.07(.09)$ & 1.07 & $.33(.09)^{* *}$ & 1.39 \\
\hline Hostile & $.63(.06)^{* *}$ & 1.88 & $.33(.07)^{* *}$ & 1.39 & $.40(.07)^{* *}$ & 1.49 & & \\
\hline Validating $^{\mathrm{a}}$ & & & & & & & $.40(.07)^{* *}$ & 1.49 \\
\hline \multicolumn{9}{|l|}{ Mother styles } \\
\hline Avoidant & $.30(.07)^{* *}$ & 1.35 & $.16(.07)^{*}$ & 1.17 & $.32(.08)^{* *}$ & 1.38 & $.07(.08)$ & 1.07 \\
\hline Volatile & $.28(.07)^{* *}$ & 1.32 & $.15(.07)^{*}$ & 1.16 & $.21(.08)^{* *}$ & 1.23 & $.18(.08)^{*}$ & 1.20 \\
\hline Hostile & $.45(.06)^{* *}$ & 1.57 & $.11(.07)$ & 1.12 & $.39(.07)^{* *}$ & 1.48 & & \\
\hline Validating $^{\mathrm{a}}$ & & & & & & & $.39(.07)^{* *}$ & 1.48 \\
\hline Intercept & $-1.49(.13)^{* *}$ & & $-.89(.14)^{* *}$ & & $11.40(.15)^{* *}$ & & $.61(.15)^{* *}$ & \\
\hline
\end{tabular}

Note: $N=15,670$. The cell where the parental conflict style and the adult children's partner's conflict style were validating was the reference group when testing the avoidant, volatile, and hostile styles

${ }^{a}$ When testing the validating group, the hostile style was used as a temporary reference group

$* p<.05, * * p<.01$

was 1.49 when they had hostile fathers and 1.48 when they had hostile mothers.

One other interesting finding we noticed was that although adult children's hostile parental conflict style predicted their partners would be hostile, it is closely followed by the likelihood of them having partners with avoidant conflict styles for males. For females it is even more likely that a hostile conflict style in the parents would be associated with an avoidant style in their partners than a hostile style in their partners. For male adult children, when they had hostile fathers, the relative risk ratio of them having hostile partners was 1.75 , followed by the likelihood of them having avoidant partners (1.62). Likewise, when they had hostile mothers, the likelihood of them having hostile partners (1.80) was followed by them having avoidant partners (1.75). For females the likelihood of them having an avoidant partner was higher (1.88) when they had a hostile father than the likelihood of them having a hostile 
partner when they had a hostile father (1.49). The same pattern emerged for female adult children's partners when they had a hostile mother.

\section{Predicting Adult Children's and Their Partners' Validating Style}

As mentioned previously, to explore validating styles, we switched out the reference cell from validating to hostile to conduct a secondary analysis. The results of this secondary analysis were included in Tables 4 to 7 in the far right columns of each table. With the hostile group as the reference, the likelihood for male adult children being validating when they had validating fathers was 3.03 times higher than the likelihood when they had a hostile father. The same pattern applied for the validating adult males and their validating mothers (2.14). These patterns indicated that parents' validating styles were the best predictors for male adult children being validating when the hostile group was the reference. Likewise, the same pattern consistently appeared for the female adult children's model, as well as both of the partners' models. Having validating parents predicted the females' validating conflict styles, and having validating parents also predicted both males and females having validating partners.

It is important to note that all numbers mentioned previously were calculated from corresponding multinomial logistic regression coefficients, which were all statistically significant at $\mathrm{p}<0.05$ level. Other results not mentioned are noted in Tables 4 through 7, which includes all coefficients, their statistical significance, and the corresponding relative risk ratios.

\section{Discussion}

The management of conflict is a crucial aspect of any relationship. Gottman and others have identified how different conflict styles are related to important relationship outcomes (Gottman 1993; Gottman 1994; Busby and Holman 2009; Holman and Jarvis 2003). What has not been studied extensively prior to the current study is the origin of these conflict styles, as well as how parental conflict styles may be associated with the conflict styles of partners. In this study, we applied Social Learning Theory to explore the associations between parents' conflict styles, the styles of their adult children, and the styles of the adult children's partners (Bandura 1971).

The results from the analyses demonstrate a significant statistical association between parents' conflict styles and those of their adult children. These results also demonstrate a linkage between parents' conflict styles and those of the partners of their adult children, though the association was less robust than those for the adult children. In general, the likelihood of having a particular conflict style as an adult was usually several times larger if the parent of either gender had that same conflict style. In some instances, such as the validating and hostile styles, the odds of having these conflict styles is close to three times as much if the parent had the same conflict style. We can see from the results that parental avoidant, validating, volatile, and hostile conflict styles all predicted the very same styles in their children. As social learning theory would suggest, this may be a manifestation of the adult children observing and then adopting their parents' conflict styles. At the least it is confirmation that adult children perceive there to be an association between the conflict styles they observed from their parents and the conflict styles they express as adults.

While it was not surprising that we found results indicating that in many instances perceived parental conflict styles were adopted by their adult children, we also wondered about the opposite effect. Since social learning theory indicates that children observe and adjust, it was likely that some children concluded through observation that certain patterns could result in undesired outcomes, and therefore they chose to develop a different conflict style or selected a partner who had a different conflict style from their parents. For example, we thought it might be the case that hostile parents could create a scenario where their children would want as little hostility as possible in their adult relationships so they might either be avoidant and/or they might select an avoidant partner. However, results showed that for the adult children themselves, when their parents were hostile, they themselves still had a higher likelihood of being hostile rather than being avoidant.

In regard to the adult children's partners, the results are informative. When the adult children had validating and hostile parents, the likelihood of them selecting a partner with the same conflict style was higher. This is consistent with the research on assortative mating (Bereczkei et al. 2003; Little et al. 2003; Zietsch et al. 2011) in that individuals with parents who had validating and hostile styles appear to be attracted to and thus have partners with similar styles. Or at least individuals with these conflict styles perceive their partners to have the same characteristics as their parents. However, in instances where the parental conflict style was avoidant, this idea of selecting a different style became apparent. When the adult children's parents were avoidant, it was the better predictor of the adult children selecting a partner with the complete opposite hostile style. Also, it is important to note that when adult children had hostile parents, although it was most likely they would also have hostile partners, the next most likely style was having avoidant partners. We believe this is indicative of a pattern we label the "reactive selection effect". 
In previous research the hostile and avoidant styles have both been linked to lower levels of relationship outcomes such as satisfaction and stability as compared to the validating style, with the hostile style being particularly detrimental (Busby and Holman 2009; Holman and Jarvis 2003). Based on the results in this study it is possible that the avoidant style, especially in regard to selecting a partner, is one way that individuals who experienced significant hostility in their families of origin try to protect themselves from more hostility. This reactive selection effect may be a reasonable short-term strategy and may serve to buffer hostile tendencies in the adult child. Still, the avoidant style, while less detrimental than the hostile style, has significant liabilities in terms of creating difficulties for couples in that some conflict just needs to be talked out and resolved which is contrary to their avoidant preferences (Gottman 1999). This is especially true when parents have adolescents who are often volatile and who will often prod parents into conflictual interactions that they may not be equipped to handle if they have only dealt with conflict through avoidance.

The substantial associations of hostile styles between parents and their adult children and their partners is distressing. The multigenerational transmission of hostility is likely associated with serious relationship distress, divorce, and multiple problems in children in these families (e.g., Scaramella and Conger 2003; Story et al. 2004). It is difficult to imagine an adult child who experienced high hostility preferring to use this approach in their relationships so it is likely that the correspondence reflects high levels of frustration with self and partner and speaks to the power of learned responses and the difficulty of breaking out of what was observed and modeled in the family of origin.

On a positive note, the strongest associations in this study were between the validating style of parents and the validating style of adult children and their partners. This style has been associated with the strongest positive outcomes for couples (Busby and Holman, 2009; Holman and Jarvis 2003), even though Gottman suggests that the avoidant and volatile styles can also be functional and satisfying. The results also show that even when parents were both hostile some children are able to develop relationships where they and their partner are both validating. It would be fruitful to carefully study this group of respondents and discover their pathways out of hostility toward a more validating style.

\section{Limitations and Future Directions}

There are limitations to consider when interpreting the results of this study. Although the sample is large, it is nonetheless nonrepresentative and may therefore produce results that cannot be generalized to all couples. For example, there appears to be an over-representation of people with college degrees, of people with certain religious denominations, and other sample characteristics (see demographic information for details). However, education, religion, and relationship status were controlled for in this study which hopefully will reduce the potential bias of these variables. Nevertheless, even with control variables the sample limitations perpetuate the problem of underrepresentation of people of certain groups in social science research and should be improved in future research. Another limitation is that the conflict styles of participants, partners, and parents were all evaluated by the same person in a cross-sectional study. Bias effects could exist when rating both self and others' conflict styles. It would improve confidence in these findings if partners and parents were asked to self-report their conflict styles. But even then, there would still likely be bias effects coming from the parents and the partners rating themselves. Perhaps the ideal research method to fully investigate this correspondence between parent and child conflict styles would be having a longitudinal design where independent observers rated conflict styles from when children were young until they were in adult relationships. Finally, the current study is not capable of controlling for all possibilities that could lead to adult conflict style development. For example, since parents and adult children often share genes, they may share similar personality traits which could influence their conflict style development. Unfortunately, questions like these cannot be answered by the current data.

While there are certainly limitations to this study, there are also some noteworthy advances from this research. For the first time parent conflict styles have been linked directly to adult conflict styles and to the styles of partners. The large size of the sample allowed for the evaluation of uncommon conflict style categories that otherwise would be impossible with a smaller representative sample. For example, with a much smaller sample, it would be much less likely to have sufficient individuals in each category to allow for analysis. The results do reveal that this intergenerational connection is worth further investigation. If future studies also reveal similar outcomes, then it is an urgent matter to engage in early intervention into conflict management processes in families so that dysfunctional or distressed family processes do not transmit to following generations. In future studies it would be helpful to do couple level analyses with parent conflict styles. It may be that similar to findings with mismatches for individual conflict styles, when there are mismatches between parents' conflict styles this has a negative effect on children (Busby and Holman 2009).

Second, even though the data for this study came from cross-sectional self-reports, it was still clear that from the adult children's perspectives, there is indeed a connection 
between perceived parental conflict styles, personal conflict styles, and partner conflict styles. In other words, regardless of the bias effects that may or may not exist during the rating process, certain conflict styles are perceived to be intergenerationally transmitted and even influence partner selection. This suggests that in order to help individuals with conflict management, it may be fruitful to discuss their current approach to conflict and how this might be related to what they experienced from their parents while growing up. Clinically there is much here that could be integrated into a variety of therapeutic models. With a few simple assessment questions about conflict styles clinicians and educators can quickly capture not only how individuals feel about their own conflict, but whether they link it to their families of origin. This can facilitate easy entry into family dynamics and discussions of how conflict can be a frustrating and difficult process to get right, especially when there were destructive models in the family of origin. Additionally the linkages to partners with a specific conflict style as a reaction to or in congruence with parents' conflict styles can facilitate couple interaction around what they appreciate from each other that is different from their families and what is the same. This can be a particularly fruitful avenue for engendering hope and positive expectations about future conflict because individuals readily remember how they felt during conflict in their families of origin. They can use conflict that went well as a model for how they want to handle matters in the future and conflict that did not go well as a reminder of how their partners and children might feel when things turn very negative. In the early stages of discussions about change it is sometimes easier and less threatening to contemplate parental styles and influences rather than what individuals find distressing about their partner's styles. As a result, rather than pitting partners against one another by discussing their frustrations with each other's conflict, it is sometimes possible to have couples come together as a team to adopt positive and reject negative models from their families of origin.

Author Contributions D.M.B.: designed and executed the study, assisted with the data analyses interpretations, and collaborated with writing all sections of the study. L.H.Y.C.: Analyzed the data, compiled the tables, and collaborated with the writing of the study.

Research Involving Human Participants All data collection procedures were approved by the institutional review board at the authors' university and were in accordance with established ethical standards for institutional and national boards.

Conflict of Interest The authors declare that they have no competing interests.

Informed Consent All participants completed an appropriate consent form prior to the completion of any data collection.

\section{References}

Ask, H., Idstad, M., Engdahl, B., \& Tambs, K. (2013). Non-random mating and convergence over time for mental health, life satisfaction, and personality: The Nord-Trondelag health study. Behavioral Genetics, 43, 108-199.

Bandura, A. (1971). Social learning theory. New York, NY: General Learning Press.

Bereczkei, T., Gyuris, P., \& Weisfeld, G. E. (2003). Sexual imprinting in human mate choice. Proceedings of the Royal Society of London, Series B: Biological Sciences, 271, 1129-1134.

Brelsford, G. M. (2013). Sanctification and spiritual disclosure in parent-child relationships: Implications for family relationship quality. Journal of Family Psychology, 27, 639-649.

Brown, A. M., Fitzgerald, M. M., Shipman, K., \& Schneider, R. (2007). Children's expectations of parent-child communication following interparental conflict: Do parents talk to children about conflict? Journal of Family Violence, 22, 407-412.

Busby, D. M., \& Holman, T. B. (2009). Perceived match or mismatch on the Gottman conflict styles: Associations with relationship outcome variables. Family Process, 48, 531-545.

Busby, D. M., Holman, T. B., \& Taniguchi, N. (2001). RELATE: Relationship evaluation of the individual, family, cultural, and couple contexts. Family Relations, 50, 308-316.

Chi, L. (2013). Intergenerational transmission of educational attainment: Three levels of parent-child communication as mediators. PsyCh Journal, 2, 26-38.

Cohan, C. L., \& Kleinbaum, S. (2002). Toward a greater understanding of the cohabitation effect: Premarital cohabitation and marital communication. Journal of Marriage and Family, 64, 180-192.

Croucher, S. M., Holody, K. J., Hicks, M. V., Oommen, D., \& DeMaris, A. (2011). An examination of conflict style preferences in India. International Journal of Conflict Management, 22, $10-34$.

Gardner, B. C., Busby, D. M., \& Brimhall, A. S. (2007). Putting emotional reactivity in its place? Exploring family-of-origin influences on emotional reactivity, conflict, and satisfaction in premarital couples. Contemporary Family Therapy, 29(Sep), 113-127.

Geher, G. (2000). Perceived and actual characteristics of parents and partners: A test of a Freudian model of mate selection. Current Psychology, 19, 194-214.

Gottman, J. M. (1993). The roles of conflict engagement, escalation, and avoidance in marital interaction: A longitudinal view of five types of couples. Journal of Consulting and Clinical Psychology, 61, 6-15.

Gottman, J. M. (1994). What predicts divorce: The relationship between marital processes and marital outcomes. Hillsdale, $\mathrm{NJ}$ : Laurence Erlbaum.

Gottman, J. M. (1999). The marriage clinic: A scientifically based marital therapy. New York, NY: Norton.

Halberstadt, A. G. (1986). Family socialization of emotional expression and nonverbal communication styles and skills. Journal of Personality and Social Psychology, 51, 827-836.

Hoffmann, J. P. (2004). Generalized linear models: An applied approach. Boston: Pearson College Division.

Holman, T. B., \& Jarvis, M. O. (2003). Hostile, volatile, avoiding, and validating couple-conflict types: An investigation of Gottman's couple-conflict types. Personal Relationships, 10, 267-282.

Little, A. C., Penton-Voak, I. S., Burt, D. M., \& Perrett, D. I. (2003). Investigating an imprinting-like phenomenon in humans partners and opposite-sex parents have similar hair and eye colour. Evolution and Human Behavior, 24, 43-51. 
Luo, S., \& Klohnen, E. C. (2005). Assortative mating and martial quality in newlyweds: A couple-centered approach. Journal of Personality and Social Psychology, 88, 304-326.

Sabatelli, R. M., Buck, R., \& Dreyer, A. (1982). Nonverbal communication accuracy in married couples: Relationship with marital complaints. Journal of Personality and Social Psychology, 43, 1088-1097.

Scaramella, L. V., \& Conger, R. D. (2003). Intergenerational continuity of hostile parenting and its consequences: The moderating influence of children's negative emotional reactivity. Social Development, 12, 420-439.

Sierau, S., \& Herzberg, P. Y. (2012). Conflict resolution as a dyadic mediator: Considering the partner perspective on conflict resolution. European Journal of Personality, 26, 221-232.

Skinner, K. B., Bahr, S. J., Crane, D. R., \& Call, V. R. A. (2002). Cohabitation, marriage, and remarriage a comparison of relationship quality over time. Journal of Family Issues, 23, 74-90.
Stanley, S. M., Markman, H. J., \& Whitton, S. W. (2002). Communication, conflict, and commitment: Insights on the foundations of relationship success from a national survey. Family Process, 41, 659-675.

Story, L. B., Karney, B. R., Lawrence, E., \& Bradbury, T. N. (2004). Interpersonal mediators in the intergenerational transmission of marital dysfunction. Journal of Family Psychology, 18, 519-529.

Topham, G. L., Larson, J. H., \& Holman, T. B. (2005). Family-oforigin predictors of hostile conflict in early marriage. Contemporary Family Therapy, 27, 101-121.

Watson, D., Beer, A., \& McDade-Montez, E. (2014). The role of active assortment in spousal similarity. Journal of Personality, 82, 116-129.

Zietsch, B. P., Verweij, K. J. H., Heath, A. C., \& Martin, N. G. (2011). Variation in human mate choice: Simultaneously investigating heritability, parental influence, sexual imprinting, and assortative mating. The American Naturalist, 177, 605-616. 